\title{
CYCLIC FATIGUE AND FRACTURE SURFACES EVALUATION OF DIFFERENT NICKEL TITANIUM ENDODONTIC FILES
}

\author{
Omar Talib Khaleefah", Ahmed Atef El-Souda ${ }^{* *}$ and Amany El-Said Badr ${ }^{* * *}$
}

\begin{abstract}
Introduction: This study compares the cyclic fatigue resistance of files made of gold technology, such as ProTaper Gold F2 and WaveOne Gold Primary files, and files made of M-Wire technology, such as ProTaper Next X2 and WaveOne files.

Materials and Methods: A total of 40 files were used in this study, which were classified into 4 groups. Cyclic fatigue tests were conducted using a cyclic loading testing machine, with an artificial canal made of stainless steel (angle of curvature: $45^{\circ}$; curvature radius: $5 \mathrm{~mm}$ ). All rotary instruments were allowed to reciprocate and rotate until complete fracture, and the fracture time was recorded in seconds using a stop watch. To prevent human error, the experiments were also video-recorded.
\end{abstract}

Results: Gold-Wire files (WaveOne Gold and ProTaper Gold) demonstrated longer time to fracture than that M-Wire files (WaveOne and ProTaper Next) $(\mathrm{P}<0.005)$. In addition, WaveOne files showed more time to fracture than ProTaper Next files $(\mathrm{P}<0.005)$. Fracture surface evaluation coincide with our results.

Conclusions: Under the conditions of this study, the gold alloy files resisted cyclic fatigue better than the M-Wire alloy files, In addition, WaveOne files resist cyclic fatigue better than ProTaper Next files.

KEYWORDS: Cyclic fatigue, scanning electron microscopy, voids, Gold technology, M-wire

\section{INTRODUCTION}

Ideally, a nickel-titanium (NiTi) rotary endodontic file should be flexible and resistant to fracture in order to enable a successful non-surgical root canal therapy to either prevent or resolve apical periodontitis through proper cleaning, shaping, disinfection, and sealing of the root canal system ${ }^{[1]}$.
A greater amount of flexibility will enable the file to follow the natural curvatures of the canals closely, incurring less unwanted forces that could result in either apical transportation or legging of the canals ${ }^{[2]}$.

There are two mechanisms which result in a NiTi rotary fracture. These include cyclic fatigue

\footnotetext{
* Department of Endodontic, Faculty of Dentistry, Mansoura University, Mansoura, Egypt
} 
fracture and torsional overloading ${ }^{[3,4]}$. Cyclic fatigue fracture occurs due to rotation around a curve by repeated extension and compression of the metal ${ }^{[3,5]}$. In contrast, torsional fracture occurs as the tip of the rotating NiTi file binds to the apical part of the canal while the motor continues to rotate $^{[3,4]}$

Examining the fracture surface (fractography) by scanning electron microscopy (SEM) usually reveals features, which help in identifying the fracture mechanism involved ${ }^{[6]}$. In brittle fractures, crack fronts create ridges that spread into several planes in the alloy, radiating away from the crack origin and leading to a V- shaped "chevron" [7].

In ductile fracture, voids are nucleated in response to the growing stress applied to the metal. These continue to develop until they touch a neighboring region in which the two voids coalesce. This occurs when the void radius exceeds half the near-neighbor spacing to form a crack, with its long axis perpendicular to the direction of the stress. The crack continues to grow in a direction parallel to its major axis by this microvoid coalescence process to develop the final fracture surface. The latter is dimpled, thereby weakening the metal and leading to fracture ${ }^{[8,9]}$.

The shapes and slopes of the dimples may reflect the type of load applied and the origin of the fracture. Ductile fractures have two modes, corresponding to tensile or shear stress. The round or spherical appearance of dimples reflects normal rupture resulting from tensile stresses (fatigue failure), whilst oval or elongated dimples reflect shear forces (torsional failure). In general, oval-shaped dimples point to the origin of the fracture ${ }^{[8]}$.

Coalescence and nucleation of the voids constitute the most common fracture initiation mechanism in ductile materials. Continuous nucleation adds small voids to the distribution, hence reducing the average void size and spacing. Continuous nucleation results in an increase in the average rate of void growth. The time to failure is shorter than that which may occur unless cavities have been nucleated beyond those present early in the life of the structure. Continuous coalescence, in contrast, removes voids from the distribution, thereby increasing the average void size and spacing. Coalescence results in a reduced average void growth rate. The time to failure is higher than that which might occur unless voids were uniformly distributed, and no coalescence occurs until the final moment of failure ${ }^{[10]}$.

In an attempt to increase the cyclic fatigue resistance of rotary instruments, the M-Wire alloy was introduced. It is produced by the serial application of special heat treatments to NiTi wire blanks. Prior to grinding, the alloy is thermally treated to improve its properties. The final goal is to produce instruments with greater flexibility and resistance to cyclic fatigue compared to the ones constructed with a traditional NiTi alloy ${ }^{[11]}$.

In a recent study, ProTaper and WaveOne systems were upgraded to ProTaper Gold and WaveOne Gold systems. The manufacturers claim that changing the heat treatment of M-Wire alloy-based files to a gold alloy treatment enables enhanced flexibility and resistance to cyclic fatigue ${ }^{[12]}$. Therefore, through this study, we compared the cyclic fatigue resistance of files made of gold technology, such as ProTaper Gold F2 and WaveOne Gold Primary files, and files made of M-Wire technology, such as ProTaper Next X2 and WaveOne Primary files.

\section{MATERIALS AND METHODS}

Forty NiTi endodontic files of the same brand (Dentsply Maillefer, Ballaigues, Switzerland) were tested in this study, including two reciprocating file systems, WaveOne Primary tip size 25, 0.08; WaveOne Gold Primary tip size 25, 0.07 taper; two rotating endodontic file systems, ProTaper Next $\mathrm{X} 2$ tip size 25, 0.06; ProTaper Gold F2 tip size 25, 0.08 taper; and 10 files from each system. All 
instruments had previously been inspected by an optical stereomicroscope at a x200 magnification to examine for any signs of deformation. None of the files were discarded.

A specially designed custom-made cyclic fatigue-testing device was used in this study. This device was modified based on previous studies ${ }^{[13,14]}$. This device comprises a mainframe supporting a stainless-steel block containing the artificial canals and a mobile support for the electric hand piece that enables the precise and simple reproducible placement of every instrument within the artificial canal, ensuring the three-dimensional alignment and positioning of the instrument to the same depth.

This simulated canal made of a stainless-steel block was first designed using specialized software (Solid Works 2012, Waltham, Massachusetts, USA.). The canal had an angle of curvature of $45^{\circ}$ with a $5 \mathrm{~mm}$ radius of curvature, as per the method of reporting canal curvature described by Pruett et al. ${ }^{[15]}$. The canal width was designed to be 0.1 $\mathrm{mm}$ larger than the original size of the instrument, enabling free rotation of the instrument within the artificial canal.

The curvature center was $1.8 \mathrm{~mm}$ from the instrument tip. This artificial canal depth was designed to be $0.5 \mathrm{~mm}$ longer than the maximum diameter of the file, allowing the file to rotate freely inside the canal. The simulated canal was covered by a tempered glass that prevented the rotary files from slipping out and allowed tight control of the reciprocating and rotating files. The artificial canal was manufactured by reproducing the instrument's size and taper. Hence, the instrument was designed with a suitable trajectory, abiding by the parameters of the selected curvature. The simulated canal was approximately $16 \mathrm{~mm}$ in length, and instruments were successfully inserted $16 \mathrm{~mm}$ into the artificial canal.
The electric handpiece was mounted over a mobile device to enable accurate and reproducible placement of all instruments within the artificial canal. The instruments from each group were driven by an electric wireless motor X-Smart IQ (Dentsply Sirona) with a cordless 8:1 reducing handpiece, allowing both reciprocating and rotational motions. The files were used according to the manufacturer's recommended speed. To reduce friction between the rotating file and the wall of the artificial canals, special high-flow synthetic oil (Super Oil; Singer Co Ltd, Elizabethport, NJ) designed for mechanical lubrication was sprayed in the canals. After positioning the instrument within the canal, all instruments were activated until fracture, and cyclic fatigue was assessed based on the time to failure.

The files allowed for free rotation and reciprocation inside the canals until fracture occurred, and the time to fracture in seconds was visually recorded using a 1/100-second-chronometer stopwatch. The motor and stopwatch were simultaneously activated. The timer was stopped when the instrument was observed to have broken. To prevent any human error, the experiments were simultaneously videorecorded, and the recordings were then assessed to cross-check the time of file separation. The length of the fractured tip was measured by a digital caliper. To remove any metal debris on the instruments, all broken instruments were first ultrasonically cleaned by an instrument cleaner. To assess fracture surfaces, all instruments were observed by SEM (JEOL $<$ JSM-6510L.USA.Inc).

\section{Statistical analysis}

The data obtained from the cyclic fatigue test were assessed for significance by a one-way analysis of variance (ANOVA) and LSD post-hoc test with the significance level set at 0.05 using SPSS 16.0 (SPSS, Chicago, IL, USA). 


\section{RESULTS}

\section{Cyclic fatigue test}

The mean along with standard deviations of the cyclic fatigue of each file, in seconds, is presented in Table 1. A longer time to fracture is caused by a higher resistance to cyclic fatigue of the tested instruments. Figure 1 represents a comparison of the mean time to fracture of the different instruments that were tested. WaveOne Gold Primary files showed significantly higher resistance to cyclic fatigue than WaveOne Primary and ProTaper Next X2 files. No significant differences were found in the resistance to cyclic fatigue with ProTaper Gold F2.

In addition, the statistical analysis showed that ProTaper Gold F2 was significantly more resistant to cyclic fatigue than WaveOne Primary and ProTaper Next X2. A post-hoc analysis showed a significantly higher resistance to cyclic fatigue in WaveOne Primary as compared to ProTaper Next X2.

\section{Fractured fragment length}

The mean length of the fractured segment was recorded to assess the correct positioning of the tested instrument in the canal curvature. The mean length of the fractured fragments of the instruments is presented in Table 2. Values are displayed in Figure 2. The length of the fractured segments ranges between 1.4 and $4.3 \mathrm{~mm}$, revealing no significant difference between the groups. The statistical analysis revealed the absence of any significant difference within the mean length of the fractured fragments of the tested instruments.

\section{SEM observations}

SEM observations of the fracture surface of the endodontic rotary instruments revealed several features, including areas of crack initiation, linear striations, dimples, voids, and regions characterized by the coalescence of voids as shown in Figure 3 and 4.

TABLE (1) Comparison of the time to failure (seconds) between different tested groups (Mean $\pm \mathrm{SD}$ )

\begin{tabular}{|l|c|c|c|c|c|}
\hline \multicolumn{1}{|c|}{ File } & $\mathrm{n}$ & Mean \pm SD & Min & Max & P Value \\
\hline WaveOne Gold & 10 & $476.20 \pm 65.54 \mathrm{a}$ & 389 & 590.60 & \\
\hline WaveOne & 10 & $343.44 \pm 68.64^{\mathrm{b}}$ & 260.50 & 503.60 & $<0.001^{* *}$ \\
\cline { 1 - 5 } ProTaper Next X2 & 10 & $214.44 \pm 43.36^{\mathrm{c}}$ & 139.10 & 283.20 & 521.20 \\
\hline ProTaper Gold F2 & 10 & $452.67 \pm 109.06^{\mathrm{ad}}$ & 332.20 & \\
\hline
\end{tabular}

A significant difference in $P$ values is marked as $a, b, c$ and $d \quad S D:$ standard deviation P: Probability *: significance $<0.05 \quad$ **: high significance $<0.001 \quad$ Test used: One-Way ANOVA followed by a post-hoc Tukey test

TABLE (2) Comparison of fragment lengths $(\mathrm{mm})$ between different tested groups (Mean $\pm \mathrm{SD}$ )

\begin{tabular}{|c|c|c|c|c|c|}
\hline File & $\mathrm{n}$ & Mean $\pm \mathrm{SD}$ & Min & Max & P Value \\
\hline WaveOne Gold & 10 & $2.21 \pm .76$ & 1.42 & 3.50 \\
\hline WaveOne & 10 & $2.74 \pm .92$ & 1.71 & 4.38 & 0.23 \\
\hline ProTaper Next X2 & 10 & $2.38 \pm .60$ & 1.69 & 3.54 & 4.25 \\
\hline ProTaper Gold F2 & 10 & $2.87 \pm .86$ & 1.67 & \\
\hline
\end{tabular}




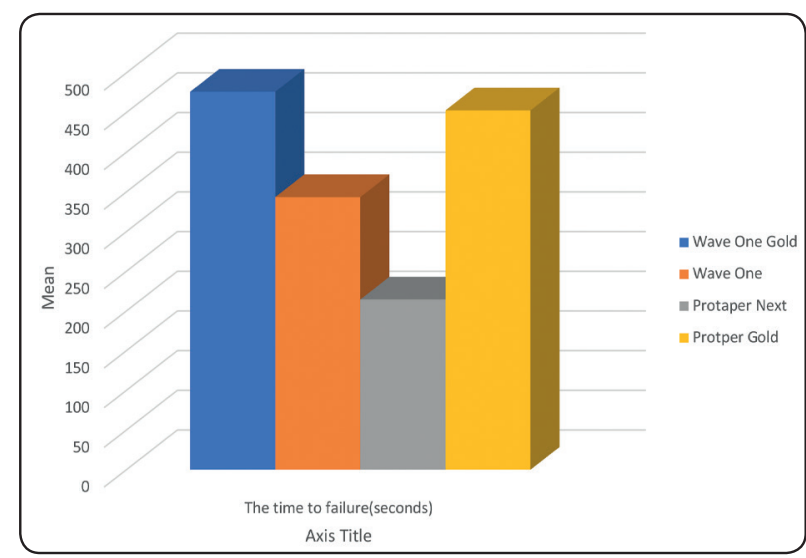

Fig. (1) Comparison between the mean time to fracture of the tested instruments

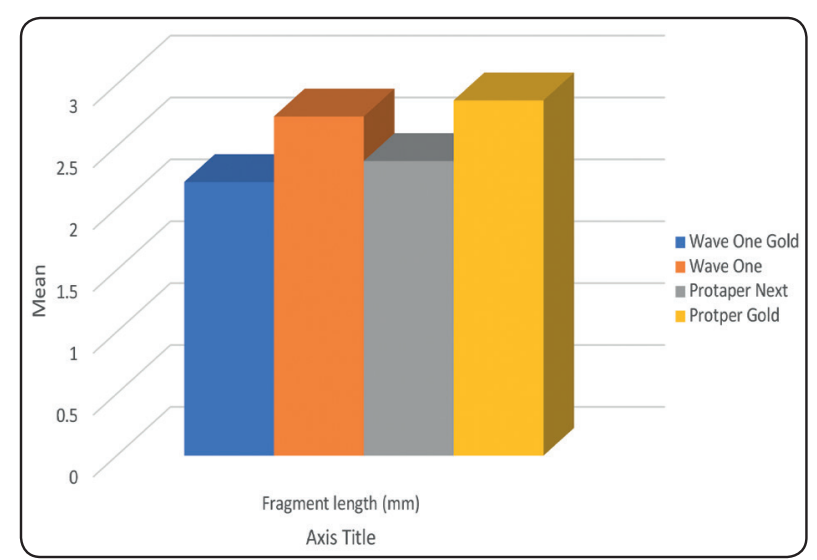

Fig. (2) Mean lengths of the fractured fragments
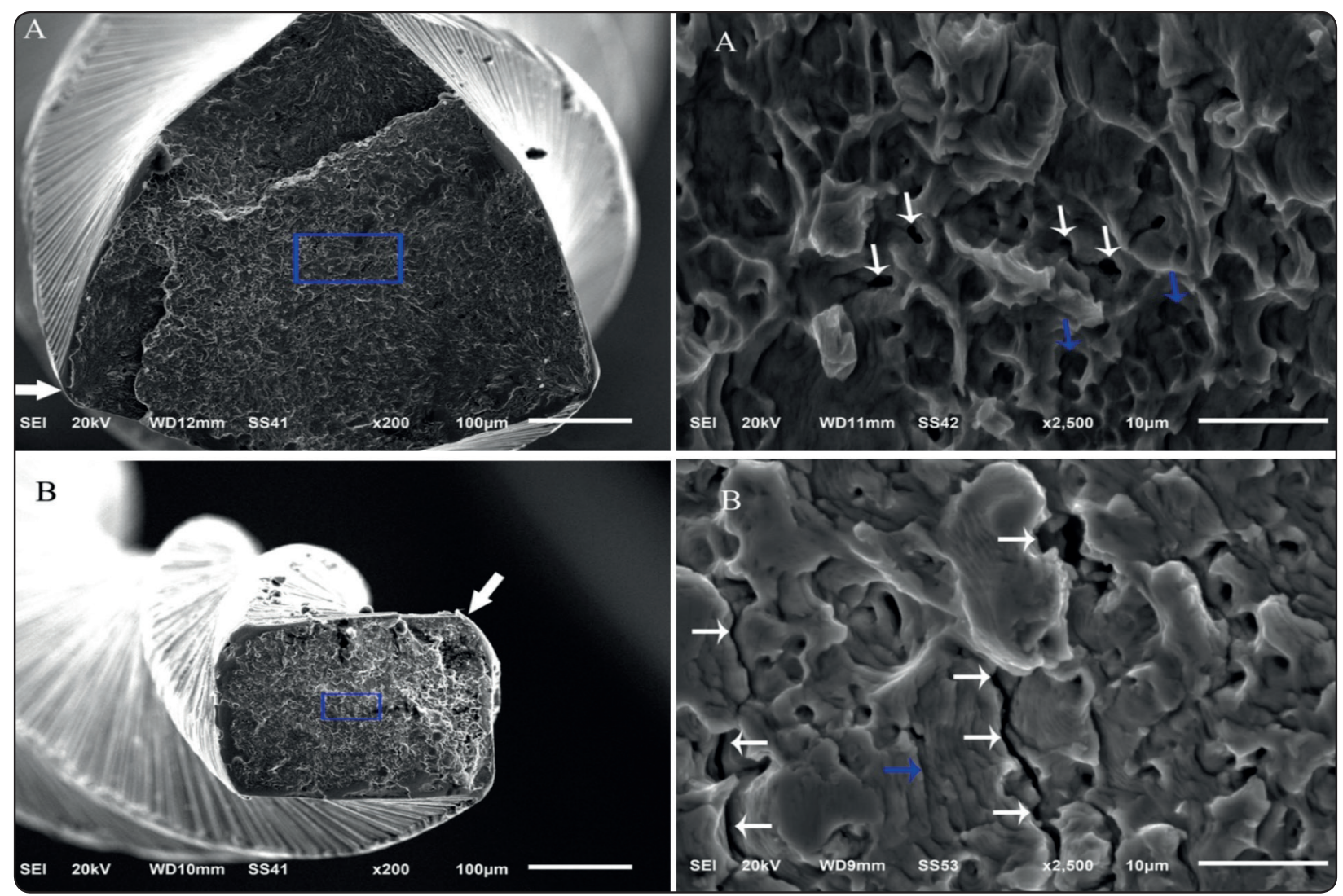

Fig. (3) Fracture surface of the instruments (a) ProTaper Gold at (x200) presented at the origin of the crack initiation (white arrow). At a higher magnification (x2500), spherical dimples (blue arrow) and voids (white arrow) are seen. (b) ProTaper Next at (x200) shows the origin of the fracture (white arrow). A higher magnification (x2500) reveals voids, the coalescence of voids (white arrow), and striations (blue arrow) 

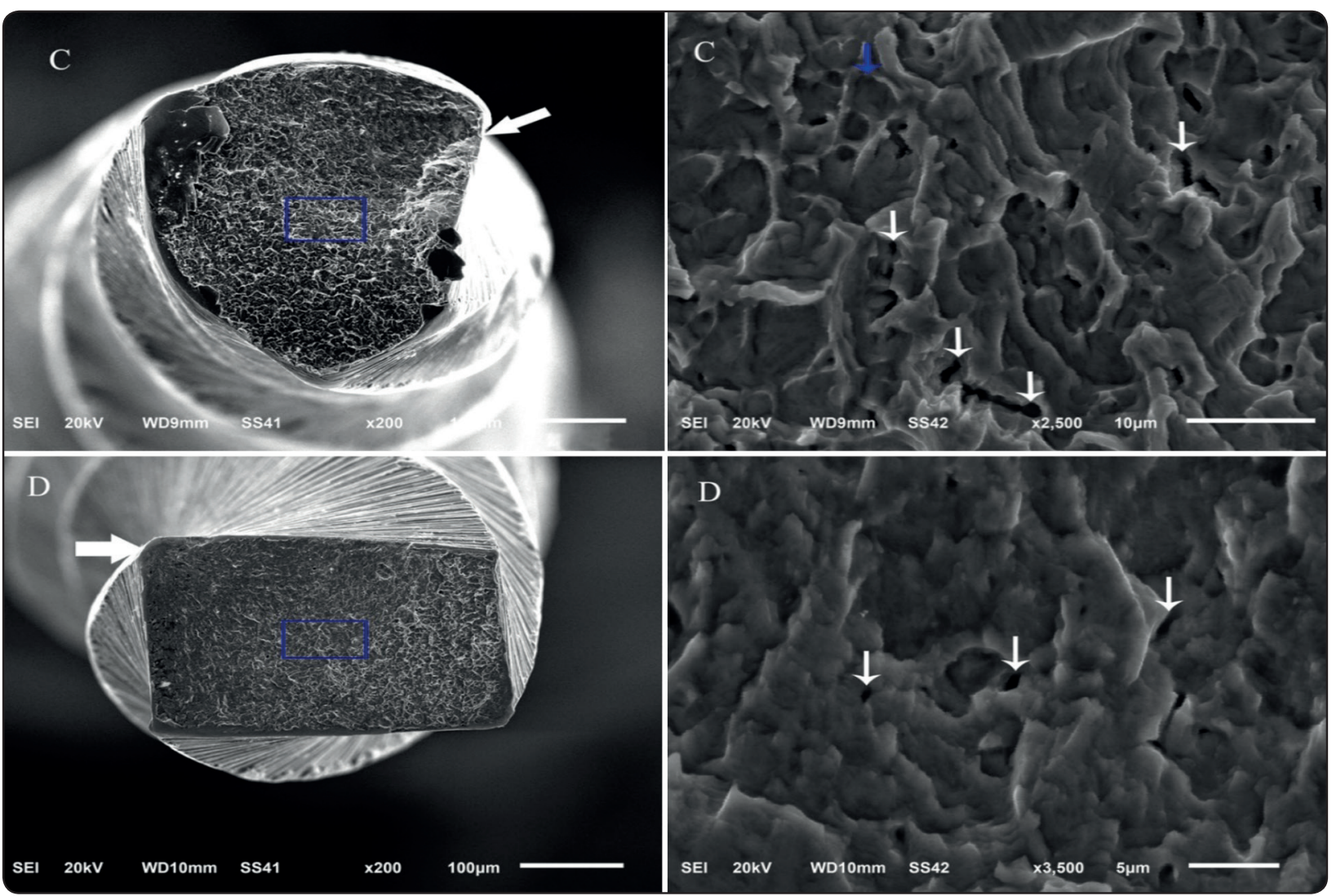

Fig. (4) Scanning electron micrographs of the fracture surface of separated fragments. (c) WaveOne file at (x200) (white arrow) indicates the origin of fracture. A higher magnification (x2500) revealed voids and the coalescence of voids (white arrow), as well as spherical dimples (blue arrow). (d) WaveOne Gold at (x200) shows the incipient crack (white arrow); at a higher magnification (x3500), voids were observed.

\section{DISCUSSION}

With no established testing norms, several experimental designs were made to be used as a block, such as 3 rigid stainless-steel pins in a pegboard ${ }^{[16,17]}$, a tempered steel rod and block assemblies ${ }^{[18,19]}$, and slots in steel form blocks ${ }^{[20]}$. A stainless-steel block was used to prevent wear of the canals during instrumentation.

Cyclic fatigue resistance in the current study was assessed by recording the time to fracture (TtF) instead of the number of cycles to fracture (NCF). Usually, the fatigue resistance of an endodontic file is tested by comparing the NCF, which is obtained by multiplying the $\mathrm{TtF}$ and the number of revolutions per second ${ }^{[21,22]}$. This is easily accomplished when comparing files with continuous rotational motion. However, to calculate NCF during reciprocating motion, it is mandatory to know the frequency of oscillation, which is not provided by manufacturers ${ }^{[23]}$. In addition, the rotational speed may not be continuous in reciprocating motion because the electrical engine is mechanically limited in converting the rotation direction, as it may contain both deceleration and acceleration within the two directions of rotation, yielding inaccurate results when calculating the NCF ${ }^{[23]}$. Besides, calculating the time until failure generates more clinically relevant information, as time is easier for operators to control than the numbers of cycles the instrument endures ${ }^{[24]}$.

The results of the cyclic fatigue test in the current study demonstrated that the WaveOne Gold Primary 
and ProTaper Gold F2 files made of gold technology had a significantly greater resistance to cyclic fatigue than the WaveOne Primary and ProTaper Next X2 files made of M-Wire. These findings are similar to those of Uygun et al. ${ }^{[25]}$. They compared the cyclic fatigue resistance of ProTaper Gold F2 and ProTaper Next X2 files. Results showed that ProTaper Gold F2 files have greater cyclic fatigue resistance than the ProTaper Next X2 files. This can be explained by metallurgic improvements to the instruments (gold technology), which increase the files' resistance to cyclic fatigue. Moreover, a cyclic fatigue resistance study of WaveOne Gold Primary files and WaveOne Primary files by Ozyurek [26] demonstrated that the WaveOne Primary files made of gold technology had significantly greater cyclic fatigue resistance than WaveOne Primary files made of M-Wire.

The transformation behavior of NiTi alloys is strongly influenced by thermomechanical treatment. Martensitic transformation occurs as a result of a 1-stage transformation (austenitic-martensitic) or a 2-stage transformation (austenitic-R-martensitic). The 1-stage transformation (austenitic-martensitic) occurs in Ni-rich $\mathrm{NiTi}$ alloys, whilst 2-stage transformations (austenitic-R-martensitic) occur after an additional heat treatment. The heat treatment creates finely dispersed $\mathrm{Ti}_{3} \mathrm{Ni}_{4}$ precipitates in the austenitic matrix. Hence, an R-Phase can be prepared instead of martensite due to the presence of fine $\mathrm{Ti}_{3} \mathrm{Ni}_{4}$ particles. However, such an alloy requires more cooling to form martensite. Thus, a martensitic transformation occurs in 2 steps (austenitic-R- martensitic) ${ }^{[27]}$. Files made of gold technology have the advantage of exhibiting a 2-stage specific transformation behavior. It has also been reported that the instruments made of gold technology have high austenite finishing temperatures, similar to a control memory wire ${ }^{[28]}$. These findings may explain the higher resistance of WaveOne Gold Primary and ProTaper Gold F2 files compared to WaveOne Primary and ProTaper Next $\mathrm{X} 2$ files.
With regard to the files' motion, the results of the cyclic fatigue test in the present study showed that a WaveOne Primary file with reciprocating motion had a significantly higher resistance to cyclic fatigue compared with a ProTaper Next X2 file with rotational motion. Using a reciprocating motion can extend the life span of the NiTi files and explain the high resistance to cyclic fatigue with a WaveOne Primary file compared to a ProTaper Next X2 file.

It has been noticed that the fracture risk of files used with continuous rotation is higher in comparison to that of files used with reciprocating motion ${ }^{[29,30]}$. Reciprocating files have been developed to reduce their incidence of breakage. Reciprocating files tend to travel a shorter circumferential distance than a rotary instrument, thereby subjecting the file to less stress ${ }^{[31]}$.

Varghese et al. ${ }^{[32]}$ assessed the cyclic fatigue resistance of WaveOne Primary size 25 files with ProTaper Next X2 size 25 files, both of which are made of M-Wire technology. The result revealed a superior resistance to cyclic fatigue in reciprocating motion (WaveOne Primary) in comparison to continuous rotation (ProTaper Next X2). Vadhaha et al. ${ }^{[23]}$ evaluated the cyclic fatigue resistance of Race (rotating motion) with Mtow (reciprocating motion), and their results demonstrated a significantly higher cyclic fatigue resistance in reciprocating motion compared to continuous rotation.

Another study by Lopes et al. [33] compared the cyclic fatigue resistance of WaveOne with reciprocating motion and ProTaper with continuous rotation. Results showed that files with reciprocating motion (WaveOne) have superior resistance to cyclic fatigue than do files with continuous rotation (ProTaper). Hence, an instrument enjoys a higher resistance to fatigue when used with reciprocating motion compared to when it is used with continuous rotation ${ }^{[34]}$. 


\section{Fractured fragment length}

The results of this study revealed no significant difference in the fracture lengths between the tested instruments. Fracture occurred at the point of maximum loading of the artificial canal, corresponding to the midpoint of the curvature. The files fractured nearly $2 \mathrm{~mm}$ from the tip of the instrument, indicating a narrow region of maximum flexure across files. The findings are consistent with those of Pruett et al. ${ }^{[15]}$ and Lopes HP et al. ${ }^{[35]}$. They evaluated the length of the instrument separation, demonstrating that instrument separation always occurs at the point of maximum flexure inside artificial canals, at the midpoint of the curved segment of the tubes.

\section{SEM observation}

This study showed that oval dimples and voids occurred in all fracture surfaces of the endodontic rotary files; these dimples are indicative of ductile fracture. The most frequently found void formation was in ProTaper Next, followed by WaveOne, WaveOne Gold, and ProTaper Gold files. These findings are consistent with our results on fatigue resistance.

\section{CONCLUSIONS}

Under the conditions of this in-vitro study:

1. The cyclic fatigue resistances of the WaveOne Gold Primary and ProTaper Gold F2 files made of gold technology were better than those of the WaveOne Primary and ProTaper Next X2 made of M-Wire.

2. WaveOne Primary reciprocating files were more resistant to cyclic fatigue than ProTaper Next $\mathrm{X} 2$ files.

3. More voids indicated rapid crack propagation.

Author contributions: This is a part of master thesis of Omar talib

\section{CONFLICT OF INTEREST}

The authors deny any conflicts of interest related to this study.

\section{REFERENCES}

1. Ørstavik D, Qvist V, Stoltze K. A multivariate analysis of the outcome of endodontic treatment. Eur J Oral Sci 2004;112:224-30.

2. Ninan E, Berzins DW. Torsion and bending properties of shape memory and superelastic nickel-titanium rotary instruments. J Endod 2013;39:101-4.

3. Sattapan B, Nervo GJ, Palamara JE, Messer HH. Defects in rotary nickel-titanium files after clinical use. J Endod 2000;26:161-5.

4. Cheung GS. Instrument fracture: mechanisms, removal of fragments, and clinical outcomes. Endod Topics 2007;16:1-26

5. Plotino G, Grande NM, Cordaro M, Testarelli L, Gambarini G. A review of cyclic fatigue testing of nickel-titanium rotary instruments. J Endod 2009;35:1469-76.

6. Karn TA, Kelly JR, Spångberg L. Fractographic analysis of experimentally separated NiTi rotary files. J Endod 2003; 29:288.

7. Le May I. Failure mechanisms and metallography: a review. in: metallography in failure analysis. Boston: Springer;1978. pp. 1-31.

8. Askeland DR, Phulé PP, Wright WJ, Bhattacharya DK. The science and engineering of materials. Dordrecht: Springer; 2003.

9. Wilkinson DS. The effect of time-dependent void density on grain boundary creep fracture-II. Continuous nucleation. Acta Metall 1987;3511:2791-99.

10. Wilkinson DS. The effect of time dependent void density on grain boundary creep fracture-i. Continuous void coalescence. Acta Metall 1987;35:1251-59.

11. Gambarini G, Plotino G, Grande NM, Al-Sudani D, De Luca M, Testarelli L. Mechanical properties of nickel-titanium rotary instruments produced with a new manufacturing technique. Int Endod J 2011;44:337-41.

12. Hieawy A, Haapasalo M, Zhou H, Wang ZJ, Shen Y. Phase transformation behavior and resistance to bending and cyclic fatigue of ProTaper Gold and ProTaper universal instruments. J Endod $2015 ; 41: 1134-38$. 
13. Elnaghy AM. Cyclic fatigue resistance of ProTaper Next nickel-titanium rotary files. Int Endod J 2014;47:1034-39.

14. Gambarini G, Grande NM, Plotino G, Somma F, Garala M, De Luca M, Testarelli L. Fatigue resistance of enginedriven rotary nickel-titanium instruments produced by new manufacturing methods. J Endod 2008; 34:1003-5.

15. Pruett JP, Clement DJ, Carnes Jr DL. Cyclic fatigue testing of nickel-titanium endodontic instruments. J Endod 1997;23:77-85.

16. Cheung GS, Darvell BW. Fatigue testing of a NiTi rotary instrument. Part 1: strain-life relationship. Int Endod J 2007;40:612-18.

17. Shen Y, Qian W, Abtin H, Gao Y, Haapasalo M. Effect of environment on fatigue failure of controlled memory wire nickel-titanium rotary instruments. J Endod 2012;38:376-80.

18. Peters OA, Barbakow F. Dynamic torque and apical forces of ProFile .04 rotary instruments during preparation of curved canals. Int Endod J 2002;35:379-89.

19. Kim HC, Yum J, Hur B, Cheung GS. Cyclic Fatigue and fracture characteristics of ground and twisted nickeltitanium rotary files. J Endod 2010;36:147-52.

20. Pérez-Higueras JJ, Arias A, José C, Peters OA. Differences in cyclic fatigue resistance between ProTaper Next and ProTaper universal instruments at different levels. J Endod 2014 40:1477-81.

21. Castelló-Escrivá R, Alegre-Domingo T, Faus-Matoses V, Román-Richon S, Faus-Llácer VJ. In vitro comparison of cyclic fatigue resistance of ProTaper, WaveOne, and twisted files. J Endod 2012;38:1521-24.

22. Kim HC, Kwak SW, Cheung GS, Ko DH, Chung SM, Lee W. Cyclic fatigue and torsional resistance of two new nickel-titanium instruments used in reciprocation motion: Reciproc Versus WaveOne. J Endod 2012;38:541-44.

23. Vadhana S, SaravanaKarthikeyan B, Nandini S, Velmurugan N. Cyclic fatigue resistance of $\mathrm{RaCe}$ and Mtwo rotary files in continuous rotation and reciprocating motion. J Endod 2014;40:995-99.

24. Arias A, Perez-Higueras JJ, José C. Differences in cyclic fatigue resistance at apical and coronal levels of Reciproc and WaveOne New files. J Endod 2012; 38:1244-48.
25. Uygun AD, Kol E, Topcu MK, Seckin F, Ersoy I, Tanriver $M$. Variations in cyclic fatigue resistance among ProTaper Gold, ProTaper Next and ProTaper Universal instruments at different levels. Int Endod J 2015;49:494-9.

26. Özyürek T. Cyclic Fatigue resistance of Reciproc, WaveOne, and WaveOne Gold nickel-titanium instruments. J Endod 2016;42:1536-9.

27. Otsuka K, Ren X. Physical metallurgy of Ti-Ni-based shape memory alloys. Prog Mater Sci 2005;50:511-678.

28. Shen Y, Zhou HM, Zheng YF, Campbell L, Peng B, Haapasalo M. Metallurgical characterization of controlled memory wire nickel-titanium rotary instruments. J Endod 2011;37:1566-71.

29. Varela-Patiño P, Martín-Biedma B, Rodriguez-Nogueira J, Cantatore G, Malentaca A, Ruiz-Pinón M. Fracture rate of nickel-titanium instruments using continuous versus alternating rotation. ENDO 2008; 2.

30. Varela-Patiño P, Ibañez-Párraga A, Rivas-Mundiña B, Cantatore G, Otero XL, Martin-Biedma B. Alternating versus continuous rotation: A comparative study of the effect on instrument life. J Endod 2010;36:157-9.

31. Wan J, Rasimick BJ, Musikant BL, Deutsch AS. A comparison of cyclic fatigue resistance in reciprocating and rotary nickel-titanium instruments. Aust Endod J 2011;37:122-7.

32. Varghese NO, Pillai R, Sujathen UN, Sainudeen S, Antony A, Paul S. Resistance to torsional failure and cyclic fatigue resistance of ProTaper Next, WaveOne, and Mtwo files in continuous and reciprocating motion: An in vitro study. $\mathrm{J}$ Conserv Dent. 2016; 19:225.

33. Lopes HP, Elias CN, Vieira MV, Siqueira Jr JF, Mangelli M, Lopes WS, Vieira VT, Alves FR, Oliveira JC, Soares TG. Fatigue life of Reciproc and Mtwo instruments subjected to static and dynamic Tests. J Endod 2013;39:693-6.

34. Lee W, Hwang YJ, You SY, Kim HC. Effect of reciprocation usage of nickel-titanium rotary files on the cyclic fatigue resistance. Aust Endod J 2013; 39:146-50.

35. Lopes HP, Moreira EJ, Elias CN, de Almeida RA, Neves MS. Cyclic fatigue of ProTaper instruments. J Endod 2007;33:55-7. 